\title{
Why Collaborate on Local Government Procurement? The Experience of UK Councils ${ }^{*}$
}

\author{
J. Gordon Murray ${ }^{1 \#}$, Peter G. Rentell ${ }^{2}$, Tina Holland ${ }^{2}$, Steven Locker ${ }^{2}$ \\ ${ }^{1}$ Dr Gordon Murray Ltd., Lisburn, UK; ${ }^{2}$ Local Government Group, London, UK. \\ Email: \#drgordonmurray@gmail.com
}

Received June 11 $1^{\text {th }}, 2011$; revised July 28 $8^{\text {th }}, 2011$; accepted August $15^{\text {th }}, 2011$.

\begin{abstract}
Within the UK public sector considerable encouragement has been given to working collaboratively on procurement. Although purchasing consortia have been a feature of the UK local government landscape and a shared services model has begun to emerge, little empirical research has been reported on whether other procurement collaborations take place, why organisations collaborate on procurement projects, what are the perceived risks and what type of procurement projects are considered suitable for collaboration. This paper reports on explorative research, to establish the answer to those questions. Suggestions are made for those considering procurement collaborative projects and further research.
\end{abstract}

Keywords: Collaboration, Public Procurement, Procurement Strategy, Procurement Organisation and Structure

\section{Introduction}

Discussion on procurement collaboration is generally concerned with "buyer and seller" vertical collaboration (for example, [1-5]. More recently that discussion has been supplemented with debating the benefits to be gained through horizontal inter-organisational collaboration with others through joining a consortium [6-12] or inter-organisation collaboration on shared services [13].

Within the UK public sector considerable encouragement has been given recently to working collaboratively on procurement, for example, the National Procurement Strategy for local government [14] the Efficiency Review [15] and Transformational Government [16]. There is a working assumption, from a policy perspective that collaboration is a good thing, yet there remains little evidence of what collaboration can extend to, beyond consortia and shared services.

The paper probes perceived potential areas for collaboration. It is concerned with the question of why public procurement organisations decide to collaborate on procurement projects. Procurement projects can be defined as a "management environment that is created for the purpose of delivering one or more business products according to a specified Business Case" or "a temporary organisation that is needed to produce a unique and pre-

\footnotetext{
*The views expressed are those of the authors and not necessarily those
} of Local Government Group. defined outcome or result at a pre-specified time using predetermined resources" [17]. Procurement projects are different from consortia or shared services in that projects have a start, a finish and an objective, while consortia and shared services are founded on the "going concern concept" [18].

The paper provides an overview of intra-organisational centralised/decentralised structures and inter-organisational consortia. It then provides an explanation of Procurement as a shared service, prior to providing case study evidence of five regional collaborations, identifying the benefits, risk and priorities for collaboration on procurement projects.

The paper contributes to theory by demonstrating, through explorative research, that a portfolio of collaboration options are open, including consortia, shared services and collaboration on procurement projects, which are complementary and not mutually exclusive. It provides evidence of the perceptions regarding the rationale, risks and priorities for procurement collaborative projects.

It contributes to practice by widening the scope of collaborations and suggesting potential opportunities, beyond consortia and shared services which could help in achieving efficiency gains.

To provide a backdrop against which collaboration on procurement projects can be compared, the next section 
discusses existing procurement structural options referred to in the literature.

\section{Procurement Organisation Structural Options}

\subsection{Intra-Organisational Procurement Structural Models}

A long-standing debate on Procurement organisational structure (going back at least until 1991 [19-21] has revolved around whether intra-organisational centralisation or decentralisation of the function is best, and how to harness internal co-ordination and collaboration. At one end of the spectrum sits the centralised model, a corporate conduit controlling procurement strategy and operational purchasing. Potentially such a unit could be positioned nationally or regionally, but most often it is at the level of the organisation. The rationale behind a centralised structural model is that it enables the organisation to concentrate its professional Procurement expertise in one place, maximise its internal organisational "leverage" and therefore extract the best deals from the market through the application of power. In parallel, having said that, such a structure is predicated on being able to have a business case justification and being able to recruit and retain appropriate Procurement professionals. However, centralisation is negatively associated with sacrificing "budget holder autonomy". In addition, with a nationally centralised unit, one of the drawbacks is that it can clash with the political and socio-economic priorities of the local council and its local/regional/national/global procurement options appraisal [22]. At the opposite end of the spectrum a decentralised structure has the corresponding pros and cons. "In practice it is seldom [decentralisation or centralisation] alone which is required but a blend of both" [19].

In what could be perceived as a compromise, a devolved structure emerged [23,24]. Primarily the model represents a shift to a 'virtual' Procurement organisation. The model aims to reap the benefits of both functional excellence, traditionally associated with a centralised organisation, at the same time gaining the coordination and economies of scale of a decentralised organisation. Van Weele and Rozemeijer [23] consider the model to be particularly appropriate to non-production areas, "where buying is of an ad-hoc nature, and where specific expertise is needed temporarily". In such situations it does not make sense to build up specific technical expertise within the Procurement function but instead to create the correct environment to ensure that cross-functional teams have the mix of expertise when it is required. The devolved model comprise of a central, small team of professionals responsible for the procurement process, procurement information systems, procurement strategy, strategic relationships, professional development, training and management development programmes. Operational purchasing is devolved to specific departments and comprises those with technical expertise of "what is bought" Effectively the devolved operational staff represent a quasi-Procurement team while remaining specialists in their own disciplines; they join with the central core to deliver their business specific procurement needs and are agents in effecting strategic procurement change.

The assumption underlying the centralised/decentralised discussion is that there will always be access to Procurement expertise within the organisation, yet anecdotal evidence suggests that is not always the case. A parallel assumption is that there will always been sufficient internal demand inside the organisation to justify the employment of a Procurement professional, yet for smaller councils such a business case may not exist.

\subsection{Consortia}

A purchasing consortium consists of two or more independent organisations that join together, either formally or informally, or through an independent third party, for the purpose of combining their individual requirements for purchased materials, services, and capital goods to leverage more value-added pricing, service, and technology from their external suppliers than could be obtained if each firm purchased goods and services alone [25].

Fundamentally a consortium is a means of outsourcing tactical purchasing. Purchasing consortia have been a feature of the UK local government landscape since the development of the Consortium of Local Authorities Special Programme in 1957 [26] but have recently gained much wider prominence.

There are an infinite array of variations within consortia [6-12] although these have a focus on harnessing combined leverage through tactical purchasing, for example bidding, supplier evaluation, negotiation and contract management [9] as opposed to wider strategic procurement roles. Their primary aim is cost reduction [9] [27] although cost reduction can mean not just lower prices but also lower transaction costs and reduced lead times [28].

Larger councils may choose to join a consortia having completed a cost/benefit analysis and decided that, within a make/buy option appraisal, the "make" (direct contracting) option is outweighed by the "buy" (access consortia contracts). The larger council may also have the expertise available to evaluate and engage with a portfolio of consortia. However, for smaller councils, which may not have access to Procurement professionals who could put in place framework arrangements, consortia are 
perceived as a cost effective way of streamlining the purchasing process and accessing greater purchasing leverage.

\subsection{Procurement as a Shared Service}

While the above were the perceived extent of structural organisational options for Procurement, Murray, et al., [13], reporting on developments within UK local government, demonstrated that a further structural model was emerging, that of Procurement as a shared service.

A Procurement shared service is one in which a number of councils jointly employ their own dedicated procurement specialist, sharing the costs, agreeing the priorities and managing performance. Effectively a shared service provides access to a Procurement specialist when the employment of such an individual would not otherwise have been considered justifiable or cost effective. The shared service can provide aggregated buying, in a similar way to a consortium, but, much more importantly, they should go beyond that tactical role and provide strategic procurement know-how for the collaborating councils. That know-how could assist in deciding in what circumstances the use of consortia is appropriate but also in providing a dedicated professional specialist, when required, to each of the participating councils and have the employing organisations priorities uppermost. Murray, et al., [38] research found evidence of councils claiming the following benefits gained through a shared service: increased purchasing power/leverage, standardised conditions of contract, common documentation, gaining access to others' expertise, sharing best practice and avoiding "reinventing the wheel". A Procurement shared service has the potential to maximise the benefits of both the intra-organisational hard core/soft core model and inter-organisational consortia participation, and is particularly relevant to smaller councils who may not otherwise have a business case justification for the employment of a Procurement specialist.

The next section provides a wider perspective on the advantages and disadvantages of collaboration.

\section{A Wider Perspective on Collaboration}

Huxham and Vangen's [29] observation is that there are a number of common rationale for collaboration: Access to resources, shared risk, efficiency, co-ordination and seamlessness, learning and the moral imperative - there is no other way.

Having said that, Huxham and Vangen [29] arrived at:

"The overwhelming conclusion from our research is that seeking collaborative advantage is a seriously resource-consuming activity so is only to be considered when stakes are really worth pursuing. Our message to practitioners and policy makers alike is don't do it unless you have to."

Such a view echoes Nollet and Beaulieu's [9] need for a strong business case and identification of both benefits and risks prior to progressing any collaboration.

Huxham and Vangen [29], referring to the need to build trust over time and manage expectations, argue that there is a need to 'start small' and incrementally build on those successes:

"Where possible, try to begin by setting yourselves some small, achievable tasks. Build up mutual trust gradually through achieving mutual small wins. If the stakes are high, you may need a more comprehensive trust-building approach.

Each time partners act together, they take a risk and form expectations about the intended outcome and the way others contribute to achieving it. Each time an outcome meets expectations, trusting attitudes are reinforced. The outcome becomes part of the history of the relationship, so increasing the chance that partners will have positive expectations about joint actions in the future. The increased trust reduces the sense of risk for these future actions."

Murray, et al. [13], when discussing a shared services approach, also argued there was a need to build up trust over time through demonstration of meaningful achievements.

This paper now considers the implications drawn from theory.

\section{Implications from Theory}

Procuring organisations have potential to benefit from collaboration. Collaboration is however considered to be a high risk and not recommended unless a cost/benefit analysis has demonstrated the anticipated benefits can not be achieved through alternative routes $[13,29]$.

It can therefore be inferred that alternative routes of making gains should be pursued prior to inter-organisational collaboration. Logically the first strategy to exhaust is that of extracting gains from intra-organisational collaboration; the hard core/soft core approach to Procurement [9] appears to provide the benefits of effectively applying Procurement expertise to gain coordination and economies of scale, and to improve procurement processes, information systems, strategy, strategic relationships, professional development and training.

However, intra-organisational economies of scale are constrained, therefore supplementing intra-organisational collaboration with inter-organisational consortia provide further scope for cost reduction through increased purchasing leverage [6-25].

For smaller organisations intra-organisational collaboration may be constrained through the absence of a Procurement professional to corral, find and access inter- 
organisational consortia. A Procurement shared service can assist in closing that gap. A shared service can deliver cost reductions through maximising the collaboration's buying leverage in addition to accessing, where appropriate, consortia. Furthermore there is evidence of shared services gaining benefits from standardising conditions of contract and documentation, and gaining access to others' expertise [30].

Therefore, it can be inferred that intra-organisational hard core/soft core, consortia, and procurement shared services all support Huxham and Vangen's [29] rational for collaborating, namely, gaining access to resources, reducing risk, efficiency, coordination and seamlessness, and learning. Indeed, the above provide an incremental route map to the theoretical need to build trust and provide demonstrable evidence over time [13,29].

Having said that, does inter-organisational collaboration have to be restricted to consortia and shared services? This paper seeks to establish is there additional scope for collaboration, on procurement projects. There is a gap in empirical research as to "why and on what" procurement inter-organisational collaboration takes place, beyond consortia and shared services; what are practitioners perceived risks, benefits and priorities? This paper reports on exploratory research to find some of the answers. It is aimed specifically at inter-organisational collaboration on procurement projects, outside the scope of consortia and shared services.

The next section sets out the research approach used and provides some background to the participants.

\section{Methods}

This research is explorative. Exploratory research is useful when there is an absence of prior research. The research does not start with "a blank sheet of paper" but instead considers the appropriateness of existing theories and their applicability to the problem under investigation. In the context of this investigation the literature review served as an appropriate means of identifying existing theories which were drawn together as implications from theory. Exploratory research is rarely conclusive; through considering patterns, ideas or hypotheses rather than testing or confirming a hypothesis it provides insights suitable for subsequent more rigorous investigation [3133]

The paper provides case study evidence, on expectations from collaborating.

Key research questions are:

1) What are the perceived and additional benefits, that couldn't otherwise be achieved, of collaborating on procurement projects?

2) What are the perceived risks of collaborating and not collaborating?
3) What type of procurement projects are considered appropriate for collaboration?

Those participating had expressed a desire to regionally explore the potential for collaboration; therefore they had previously demonstrated willingness, in spirit, to collaborate and are a purposive sample of 32 English councils spanning five collaborations:

"Purposive sampling is a type of non-probability sampling method in which the researcher uses his or her own judgement in the selection of sample members. It is sometimes called a judgemental sample [31].

Purposive sampling involves choosing people whose views are relevant to an issue because you make a judgement, and/or your collaborators persuade you that their views are particularly worth obtaining and typify important varieties of viewpoint [34].

Purposive sampling allows us to choose a case because it illustrates some feature or process in which we are interested [35]."

Web-based questionnaires and facilitated workshops were used.

Due to the workshop nature it was decided to limit the number of participants to twenty-five and therefore identifying the core participants from each authority was important. Each of the participating councils was therefore asked to nominate three participants for the collaboration project, to include the officer procurement champion and officer responsible for procurement strategy development and implementation. Other potential nominees could include internal audit staff or finance staff. Drawing from a wide cross-section of stakeholders from each council, although not including politicians, hoped to protect against purchasing manager myopia and improve the validity $[36,37]$.

Prior to the workshops each delegate was sent a webbased questionnaire which sought to establish, through open-ended questions, which included:

1) Their perceived aims for the collaboration as a whole, that is, what the collaboration should set as primary aims;

2) What they perceived the collaboration can do that the individual council can't do;

3) What were the existing areas of coordination and collaboration between those councils participating in the initiative;

4) What were their immediate priorities for the collaboration;

5) How coordinated is purchasing within their council (for example framework arrangements);

a) Categories of contracts let;

b) Expiry dates of above;

6) What use they made of existing framework agreements (from other councils). 
The responses from the questionnaires enabled each discrete workshop to be tailored by the individual participants' views, which may not have been expressed in an open forum.

At the workshop, following an introduction to collaboration, summary feedback was provided from the pre-workshop questionnaires on participants' collaboration aims. Those prompts were then used by workshop groups to reach agreement, but not necessarily consensus, on aims, priorities and timescales for inter-organisational collaboration.

The outputs were analysed utilising "pattern matching" [38] against the pre-determined research questions.

The unit of analysis regarding "benefits" is the individual council, while for "risks"" and "priorities" the unit of analysis is each of the five collaborations.

The research is explorative and therefore generalisations beyond those collaborations reported should be made, only with caution.

\section{The Cases}

The cases represent a diverse mix, spend, geographically, size and type of councils. However, each of the collaborations had some previous experience of collaborating and therefore, it can be assumed, built up some trust.

Of those councils participating in the research, $46 \%$ were districts; $55 \%$ had a corporate procurement unit led by a professional head of procurement $-45 \%$ didn't or didn't know; 94\% had a corporate procurement strategy and $73 \%$ had procurement strategies which set out their approach to collaboration; $79 \%$, at that time, had been collaborating with other councils; $90 \%$ made use of consortia and $77 \%$ made use of public sector frameworks arrangements.

\subsection{Collaboration A}

Collaboration A was between nine councils. Two of the districts had previously opted to deliver Procurement as a shared-service and participated in Murray, et al's. [13] research. Prior to this research there had been previous examples of collaboration, although that had generally been between two or three councils. Examples of previous collaborations included a joint P2P system. The majority of those in the collaboration made use of consortia and other public sector framework arrangements. A regional procurement officer group met regularly.

\subsection{Collaboration B}

Collaboration B was between three councils. All three of the councils had a history of collaboration with each other, for example, they jointly procured a spend analysis and, at the time of the investigation, were working on a joint telecommunications strategy. Two of the councils make use of an e-marketplace.

\subsection{Collaboration $C$}

Collaboration $\mathrm{C}$ comprised five councils. Those participating were a sub-group of a wider procurement officer network, comprising county and district councils, police, fire and NHS bodies.

\subsection{Collaboration D}

Collaboration D comprised ten councils. All of the councils had a long history of working collaboratively. Unlike the other cases, this collaboration participated in the project with a pre-defined e-procurement collaborative objective project in mind.

\subsection{Collaboration E}

Collaboration E comprised five councils. Four of the five councils use the same core financials platform.

\section{Findings}

\subsection{Perceived Benefits of Participating in Collaboration and Added Value through Collaborating.}

The responses generally echoed the rationale put forward by Huxham and Vangen [29] for collaboration, namely, access to resources, efficiency, coordination and seamlessness, and learning. While none of the participants identified sharing best practice as a perceived benefit, $25 \%$ recognised that as something which in the absence of collaboration would not otherwise be achieved. Other significant findings were the comparatively close correlation between perceived benefits and unique collaboration benefits gained on shared back office cost reductions and, standardisation of contract and specifications. This would suggest that the participants felt that they had reached a ceiling of what improvement that could be achieved elsewhere. 55\% of the participant organisations had a Procurement Unit led by a Procurement professional but only $9 \%$ of the participants felt the only way of gaining access to experience and capability lay in collaboration; the assumption is made that $16 \%$ of those who envisaged this as a collaborative benefit had identified other potential options. It may also be relevant that since $90 \%$ of the participants already made use of consortia and $77 \%$ made use of other public sector framework arrangements.

Surprisingly none of the participants identified shared risk as a benefit.

However, what does appear to have been presented is at least a business case rationale for collaborating on procurement projects which goes some way to satisfying Huxham and Vangen [29] and, Nollet and Beaulieu [9] 
recommendations.

\subsection{Perceived Risks}

Huxham and Vangen [29] and, Nollet and Beaulieu [9] highlighted that collaboration is not easy. Across the five workshops there was no consistency regarding the perceived risks of collaboration.

Huxham and Vangen [29] suggested that each time parties act together they take a risk, a risk that the others may not honour their commitments. $75 \%$ identified a potential conflict of priorities between those of the collaboration and the participating individual councils in that this could lead to their participating councils individual priorities being subsumed by others. This emphasises the importance of ensuring that those negotiating collaborations have the required authority to act as agents of their organisation. It appears an anomaly that none of the participants viewed the risk of others not honouring their commitments to the collaboration as a risk. 50\% identified a lack of control over their own council's behaviour as a risk-in other words they were concerned whether they had the authority to act as the principal and whether they could actually sell the commitments which they made back at their own council.

There was much more consensus on the risks of NOT collaborating. All expressed a risk of 'standing still and getting left behind', and duplication of effort.

$75 \%$ perceived not collaborating risked higher costs, efficiencies not being achieved and forgone benefit of wider expertise and loss of learning opportunities gained from others.

$50 \%$ expressed concern that they'd potentially miss out on best practice and there'd be a lost opportunity of leverage.

\subsection{Identified Priorities for Collaboration}

The workshops were designed to have a practical outcome, that of agreeing initiatives to collaborate on, then taking the two which had the highest local priority and developing action plans for their achievement. The implementation of the action plan is beyond the scope of this paper.

While caution is required in interpreting the results owing to the reality that each of the workshop collaborations were starting from different historical backgrounds and therefore had differing needs, the findings are illustrative of what are viewed by councils as potentially suitable for procurement collaborative action, for example, high priority was given to: developing a common contracts register; a common supplier adoption strategy for e-procurement; joint e-procurement strategy; common documentation across the collaborating authorities; joint use of a supplier portal; joint e-sourcing system; common pre-qualification system; and common contract management approach.

\section{Discussion and Conclusions}

This paper provides an overview of differing approaches to collaboration on procurement.

The participating authorities had some previous experience of working collaboratively; and many had Procurement professionals, strategies and collaboration strategies in place, so making generalisations on the cases requires caution.

However, the significance of two of the councils within Collaboration A also having been engaged in Murray, et al., [13] research on Procurement shared services should not be under-estimated as it provides evidence of the same councils making use of three interorganisational collaborations types, namely consortia, shared services and collaboration on procurement projects. Recognising that confirms councils have a portfolio of inter-organisational collaboration options, which are not mutually exclusive, and it is therefore important that, in seeking to achieve the optimum mix, an extensive options appraisal is undertaken.

Given that consortia, shared services and project collaborations are part of a mix of inter-organisational options, practitioners should familiarise themselves with the relative merits and identify the best fit within their procurement strategies.

It can be inferred that intra-organisational collaboration, consortia, and procurement shared services all support Huxham and Vangen's [29] rational for collaborating, namely, gaining access to resources, reducing risk, efficiency, coordination and seamlessness, and learning. Indeed, the above provide an incremental route map to the theoretical need to build trust and provide demonstrable evidence over time [29].

Collaborations need to be entered into with care, it therefore makes sense to first maximise the benefits to be achieved through intra-organisational coordination and collaboration.

Evaluate the range of potential inter-organisational collaboration options, including consortia, shared services and collaboration on procurement projects to gain the optimum mix.

Spend time on in-house preparation prior to actively participating on collaborations and ensure that those negotiating the collaboration have the appropriate authority to honour commitments given as a failure to honour commitments could jeopardise future collaborations. Determine the costs associated with collaboration and the benefits to be achieved through collaboration - the added value.

Adopting an incremental approach to collaboration can 
be expected to reap benefits and reduce risks. Useful areas worthy of consideration for collaboration on procurement projects include developing a common contracts register, and common documentation across the collaborating authorities; from that the collaboration could progress to a common pre-qualification system and common contract management approaches, followed by a joint e-procurement strategy, common supplier adoption strategy for e-procurement, joint use of a supplier portal and joint e-sourcing system.

At the level of the collaboration, it is suggested that, priorities should be set at an appropriate level, cognisant of the level of trust built up from previously working together; look for convergence of priorities and mutual gain, ensuring that there is no conflict with participating councils own individual priorities-synergy and value added should be the mantras of the collaboration-otherwise they have the potential to be dysfunctional; have clearly defined objectives for each project with a start and a finish.

Perceived benefits of collaborating on procurement projects echoed those previously found with Procurement shared services, namely, efficiency gains through increased purchasing power/leverage, standardised conditions of contract, common documentation, gaining access to others' expertise, sharing best practice and avoiding "reinventing the wheel". Other perceived benefits in collaborating are reducing back office transaction costs, standardisation of specifications and networking opportunities. Therefore the research generally supports [29] assertions on common rationale for collaboration. It is considered significant that these perceived benefits are beyond a number which could be expected from tactical collaboration through consortia.

Key risks associated with collaboration are the potential conflict with partners individual priorities, with collaboration's priorities being subsumed by those of the individual participating council. A further concern is the risk that those representing the council may not have the authority to implement agreed outcomes within their own councils. This emphasises the need to ensure that those negotiating collaborations should have the required authority and gravitas to carry through commitments to implementation.

Opting not to collaborate with others is not risk free bearing in mind Huxham and Vagen's [29] "health warning" on collaboration, "don't do it unless you have to"-it brings with it the potential of "getting left behind", missing out on others experience and expertise, duplication of effort, higher costs, loss of purchasing leverage and potentially failing to achieve external targets with the associated the penalty of a lower score in external performance inspections.
Among a wide range of potential collaborative projects, participants gave priority to developing a common contracts register, standardising on documentation, introducing a common pre-qualification system and a common contract management approach, together with a collaborative approach to e-procurement strategy (including, joint use of a supplier portal and a joint e-sourcing system). The assumption is that synergies associated with these priorities out-weighed the associated risks.

\section{Conclusions}

As pressure increases on UK councils to achieve cost reductions, it can be expected that there will be a need to find increasingly innovation means of squeezing the diminishing intra-organisational potential. One of the options open is to increase the scope of inter-organisational collaboration opportunities through consortia participation, shared services and procurement projects.

This paper demonstrates, through explorative research, that a portfolio of collaboration options are open, including consortia, shared services and collaboration on procurement projects, which are complementary and not mutually exclusive, and provides evidence of the perceptions regarding the rationale, risks and priorities for procurement collaborative projects.

This research provides evidence that inter-organisational collaboration on procurement can be beyond participation in a consortium or shared service-there can be collaboration on procurement projects.

Recognising that portfolio of inter-organisational collaboration options, research would be merited which further explores the relative merits and appropriateness, and other options for inclusion in procurement options appraisal.

Further research would be merited that tests the explorative findings and their generalisabilty across a range of projects (procurement and non-procurement). While the research identified potential areas for collaboration on procurement projects, further research would be merited which identifies which types of procurement projects are not suitable for collaboration, if any. Further research, through a longitudinal study, would be of benefit that establishes the dynamics of how collaborations evolve, the problems encountered and how they're overcome in seeking to project manage collaborative projects.

\section{Acknowledgements}

The support and assistance of the anonymous participants in this investigation is gratefully acknowledged.

\section{REFERENCES}

[1] R. Lamming, "Beyond Partnership: Strategies for Innovation and Lean Supply," Prentice Hall, London, 1993. 
[2] A. Erridge and J. G. Murray, "Lean Supply: A Strategy for Best Value in Local Government," Public Policy and Administration, Vol. 13, No. 4, 1998, pp. 70-85. doi: $10.1177 / 095207679801300206$

[3] M. Barratt, "Understanding the Meaning of Collaboration in the Supply Chain," Supply Chain Management: An International Journal, Vol. 9, No. 1, 2004, pp. 30-42. doi:10.1108/13598540410517566

[4] Y. Fu and R. Piplani, "Supply-Side Collaboration and Its Value in Supply Chains," European Journal of Operational Research, Vol. 152, No. 1, 2004, pp. 281-288. doi:10.1016/S0377-2217(02)00670-7

[5] P. Cousins, "The Alignment of Appropriate Firm and Supply Strategies for Competitive Advantage," International Journal of Operations and Production Management, Vol. 25, No. 95, 2005, pp. 403-428. doi:10.1108/01443570510593120

[6] U. Arnold, "Purchasing Consortia as a Strategic Weapon for Highly Decentralised Multi-Divisional Companies: Finding from four case studies," In: G. Capaldo, E. Espoitio, C. lo Storo and M. Raffa, Eds., Supply Management, Ingegneria Economico-Gestionale, Italy, 1998, pp. 34-54.

[7] M. Essig, "Purchasing Consortia as Symbiotic Relationships: Developing the Concept If 'Consortium Sourcing'," European Journal of Purchasing and Supply Management, Vol. 6, No. 1, 2000, pp. 13-22. doi:10.1016/S0969-7012(99)00031-3

[8] F. Rozemeijer, "How to Manage Corporate Purchasing Synergy in a Decentralised Company? Towards Design Rules for Managing and Organising Purchasing Synergy in Decentralised Companies," European Journal of Purchasing and Supply Management, Vol. 6, No. 1, 2000, pp. 5-12. doi:10.1016/S0969-7012(99)00034-9

[9] J. Nollet, and M. Beaulieu, "Should an Organisation Join a Purchasing Group?" Supply Chain Management: An International Journal, Vol. 10, No. 1, 2005, pp. 11-17. doi:10.1108/13598540510578333

[10] E. Bakker, H. Walker and C. Harland, "Organising for Collaborative Procurement: An initial conceptual framework," In: G. Piga and K. V. Thai, Eds., Advancing Public Procurement: Practices, Innovation and Knowledgesharing, PrAcdemics Press, Florida, 2006, pp. 14-44.

[11] C. McCue and E. Prier, "Using Agency Theory to Model Cooperative Public Purchasing," In: G. Piga and K. V. Thai, Eds., Advancing Public Procurement: Practices, Innovation and Knowledge-Sharing, PrAcdemics Press, Florida, 2006, pp. 45-70.

[12] A. Vereecke and S. Muylle, "Performance Improvement through Supply Chain Collaboration in Europe," International Journal of Operations and Production Management, Vol. 26, No. 11, 2006, pp. 1176-1198. doi:10.1108/01443570610705818

[13] J. G. Murray, P. Rentell and D. Geere, "Procurement as a Shared Service in English Local Government," International Journal of Public Sector Management, Vol. 21, No. 5, 2008, pp. 540-555. doi:10.1108/09513550810885822
[14] ODPM/LGA (Office of the Deputy Prime Minister/Local Government Association) National Procurement Strategy for Local Government, ODPM, London, 2003.

[15] P. Gershon, "Releasing Resources to the Front Line: An Independent Review of Public Sector Efficiency," HM Treasury, London, 2004.

[16] Cabinet Office, "Transformation Government: Enabled by Technology," Cm 6683, 2005.

[17] Office of Government Commerce, "Managing Successful Projects with PRINCE2," TSO, London, 2002.

[18] J. Sizer, “An Insight into Management Accounting," Penguin Books, London, 1985.

[19] IPS (Institute of Purchasing and Supply), "Purchasing: Role and Organisation," Institute of Purchasing and Supply, Stamford, 1991.

[20] P. Baily, D. Farmer, J. Jessop and D. Jones, "Purchasing Principles and Management," 7th Edition, Pitman, London, 1994.

[21] A. J. van Weele, "Purchasing Management," Chapman and Hall, London, 1994.

[22] J. Hughes, M. Ralf and B. Michels, "Transform Your Supply Chain: Releasing Value in Business," International Thomson Business Press, London, 1998.

[23] IPS (Institute of Purchasing and Supply), "Purchasing: Role and Organisation," Institute of Purchasing and Supply, Stamford, 1991.

[24] A. J. van Weele, and F. Rosemijer, "Getting Organised for Purchasing and Supply Management in the Information Age; towards the Virtual Purchasing Organisation?" Proceedings of 2nd Worldwide Research Symposium in Purchasing and Supply Management, London, 1998, pp. 421-431.

[25] R. Russill, "Purchasing Power: Your Suppliers, Your Profits," McGraw Hill, London, 1997.

[26] T. Hendrick, "Purchasing Consortiums: Horizontal Alliances among Firms Buying Common Goods and Services. What? Who? How?" Centre for Advanced Purchasing Studies, Tempe, 1997.

[27] IMTA (Institute of Municipal Treasurers and Accountants) "Central Purchasing," IMTA, London, 1963.

[28] T. Kivisto, V.-M. Virolainen and E. Tella, "Consortia Purchasing and Logistics in the Kuopio Area," In: L. Knight, C. Harland, J. Telgen, K. V. Thai, C. Callendar and H. McHen, Ed., Public Procurement: International case and Commentary, Routledge, London, 2007, pp. 190-201.

[29] M. M. Aylesworth, "Consortia Purchasing for Higher Education in Canada, the US, the UK and Australia," In: L. Knight, C. Harland, J. Telgen, K. V. Thai, C. Callendar and H. McHen, Ed., Public Procurement: International Case and Commentary, Routledge, London, 2007 pp. 176-189.

[30] C. Huxham and S. Vangen, "Managing to Collaborate," Rutledge, London, 2005.

[31] E. Babbie "The Practice of Social Research," 7th Edition, 
Wadsworth, Belmont, 1995.

[32] E. M. Phillips and D. S. Pugh, "How to Get a PhD: A Handbook for Students and Supervisors," Open University Press, Buckingham, 1994.

[33] J. Hussey and R. Hussey, "Business Research," Palgrave, London, 1997,

[34] A. D. Jankowicz, "Business Research Projects," 2nd Edition, Chapman and Hall, London, 1995.

[35] D. Silverman, "Doing Qualitative Research,” Sage, Lon- don, 2000.

[36] A. Sayer, "Realism and Social Science," Sage, London, 2000.

[37] J. G. Murray, "Improving the Validity of Public Procurement Research," International Journal of Public Sector Management, Vol. 22, No. 2, 2009, pp. 91-103. doi:10.1108/09513550910934501

[38] R. K. Yin, “Case Study Research,” Sage, London, 1994. 